\title{
Pretransplant helper T-lymphocyte determination in bone marrow donors: acute graft-versus-host disease prediction and relation with long-term survival
}

\author{
M. W inandy, ${ }^{1}$ P. Lewalle, ${ }^{2}$ V. Deneys, ${ }^{1}$ A. Ferrant $^{2}$ and M. De Bruyère ${ }^{1}{ }^{1}$ Université Catholique de Louvain, \\ Immunohaematology, Brussels, and ${ }^{2}$ Cliniques Universitaires Saint-Luc, Haematology JOU, Brussels, Belgium
}

Received 31 August 1998; accepted for publication 18 December 1998

\begin{abstract}
Summary. Helper T-lymphocyte precursor (HTLp) frequency from 19 allogeneic bone marrow donors was tested to detect weak antigenic differences with the recipient, and then compared to the outcome. HTLp frequency was estimated in limiting dilution cultures, and HLA-DR and CD 80 expression by stimulating cells was measured by flow cytometry. 12/19 patients experienced acute graft-versus-host disease (aGVHD) grade II-IV. A good correlation was found between high pretransplant HTLp frequency and grade II-IV aGVHD (median: 1/55848 PBMNC for II-IV GVHD versus 1/ 184346 for $0-$ I GVHD; $P=0.008$ ). Sensitivity was $82 \%$, specificity $63 \%$, negative predictive value $71 \%$ and positive
\end{abstract}

predictive value $75 \%$. Long-term survivors also had a lower HTLp median frequency (1/143354) when compared with patients who died as a result of the transplant procedure $(1 / 22100, P<0.001)$. No correlation was found between HTLp frequency and HLA-DR or CD80 expression by patient's cells. We conclude that HTLp frequency estimation can predict, although poorly, acute GVHD risk and long-term survival.

Keywords: helper T-lymphocyte precursor frequency, acute graft-versus-host disease prediction, bone marrow transplantation, long-term survival prediction.
Despite recent progress in compatibility tests performed before bone marrow transplantation (BMT), it is still difficult to predict graft-versus-host disease (GVHD). Many allografted patients suffer from this wide immune reaction. Direct mortality or severe morbidity post transplantation may be related to GVHD in $25 \%$ of patients (Ferrara \& Deeg, 1991; Hansen et al, 1995). Therefore much has been done to avoid and treat this syndrome, using immunological, epidemiological and pharmacological approaches.

The risk factors for developing GVHD are well known. They include HLA disparities between donor and recipient, older age, female donor with male recipient, an unrelated donor and previous viral infections (van Bekkum, 1991; Kelemen et al, 1993; Kalhs, 1993; Appleton \& Sviland, 1993; Aschan et al, 1994). However, even when the risk of developing a GVHD is small, it remains a problem when the graft has not been T-cell depleted.

Correspondence: Dr M. Winandy, Université Catholique de Louvain, Laboratiore d'Immunohématologie, Clos Chapelle-aux-Champs, 30.52, B-1200 Bruxelles, Belgique. e-mail: deneys@sang.ucl.ac.be.
Thus, in vitro functional tests have been designed to predict the risk for GVHD for each donor-recipient pair. The mixed lymphocyte reaction (MLR) has been widely used, but analyses on large numbers of patients did not show any correlation between a high response index and GVHD occurrence (Segall et al, 1996; Mickelson et al, 1996). Recently, several groups have tested donor immunological response to patient antigens in limiting dilution assays (LDA). These quantitative assays have been designed to estimate cytotoxic or helper $\mathrm{T}$ lymphocyte precursor frequencies (CTLp, HTLp). The predictive value obtained of tests seemed better than those of MLR. Host-reactive precursors frequency was often related to HLA or minor histocompatibility mismatches (Theobald et al, 1992; Schwarer et al, 1994; Spencer et al, 1995a, b; Bunjes et al, 1995; Potolicchio et al, 1996; Keever-Taylor et al, 1997; van der Meer et al, 1997).

On the basis of these encouraging results, we decided to test allogeneic bone marrow adult donor HTLp frequency. As class II HLA molecules are essential for antigen presentation to $\mathrm{CD} 4^{+} \mathrm{T}$ cells, their expression on a patient's 
peripheral blood mononuclear cells (PBMNC) was measured by flow cytometry. CD 80 (B7.1) molecule expression was also measured to investigate the co-signalling capacity of these cells. The results were then compared with clinical events.

\section{MATERIALS AND METHODS}

Patients. We studied bone marrow donor alloreactivity to the antigens of 19 patients. These patients were allografted at our centre between 1989 and 1996. The median age at transplant was 45 years (range 24-59); donor median age was 38 (range $30-46$ ). Donors were HLA-identical siblings (17) or volunteer unrelated donors (two). Diagnoses were severe aplastic anaemia (one), acute lymphoblastic leukaemia (two), chronic lymphocytic leukaemia (two), acute myeloid leukaemia (one), chronic myeloid leukaemia (five), non-Hodgkin's lymphoma (four), myelodysplastic syndrome (one) and multiple myeloma (three). Four patients had advanced disease (later than first remission or acute-phase $\mathrm{CML}$ ) and 15 had standard-risk disease (first complete remission or first chronic phase). None of the grafts was Tcell depleted. Conditioning regimen before BMT and other patient characteristics are shown in Table I. Acute GVHD was graded according to established criteria (Przepiorka et al, 1995).

HLA typing. Class I HLA molecules were serologically determined for all donor-recipient pairs. Class II molecules or genes were typed with the following methods: serology (patients 3, 5, 8, 15, 16 and 18); PCR-RFLP (patients 1, 3, 9, 14, 15, 17 and 18); reverse dot blot (patients 1, 2, 4, 6, 10, $11,12,13,16$ and 19), and PCR-SSP (patients 6, 10, 11, 12, 16,18 and 19). For 10 patients a combination of several of these methods was necessary to reach a high resolution typing. For patients 5 and 8, class II HLA molecules were typed only by serology. Patient 3 had a HLA-DR 6 allelic difference with his unrelated donor detected by RFLP.

Harvesting and cryopreservation of donor and patient PBM NC. Heparinized or citrated blood from patients and their bone marrow donor was harvested within the 2 weeks preceding BMT, separated on Ficoll-Hypaque (density $=1.077$, International Medical, Belgium), washed three times in RPMI 1640 medium (Gibco) and cryopreserved in liquid nitrogen at $5 \times 10^{6}$ cells $/ \mathrm{ml}$ in RPMI 1640 containing $20 \%$ heat-inactivated normal $A B$ human pooled serum, glutamin $(1.5 \mathrm{~mm})$, penicillin $(50 \mathrm{U} / \mathrm{ml})$, streptomycin $(50 \mu \mathrm{g} / \mathrm{ml})$, gentamycin $(500 \mu \mathrm{g} / \mathrm{ml}$ ) (all from Gibco) and $10 \%$ dimethylsulphoxide (Merck, Belgium).

$M$ aintenance of IL-2-sensitivecell line A9.12. The A9.12 cell line was cultivated in RPMI 1640 supplemented with $10 \%$ heat-inactivated fetal calf serum (Gibco), glutamine $(1.5 \mathrm{~mm})$, hepes buffer $(10 \mathrm{~mm})$, sodium pyruvate $(2 \mathrm{~mm})$, 2-mercaptoethanol $\left(5 \times 10^{-5} \mathrm{M}\right)$, penicillin $(50 \mathrm{U} / \mathrm{ml})$, streptomycin $(50 \mu \mathrm{g} / \mathrm{ml})$, and gentamycin $(500 \mu \mathrm{g} / \mathrm{ml})$. Recombinant human IL-2 (Eurocetus) was added to reach a final concentration of $100 \mathrm{IU} / \mathrm{ml}$. Cells were divided every 2 or $3 \mathrm{~d}$

Table I. Patient diagnoses and conditioning.

\begin{tabular}{rlllllll}
\hline UPN & Patient sex & Donor sex & Patient age & Donor age & Donor type & Diagnosis & Conditioning \\
\hline 1 & M & M & 53 & 47 & ID & ALL (s) & 1 \\
2 & M & F & 33 & 30 & ID & NHL (s) & 1 \\
3 & M & F & 25 & 33 & MUD & CML (a) & 1 \\
4 & F & M & 47 & 46 & ID & NHL (s) & 1 \\
5 & F & M & 49 & 59 & ID & NHL (a) & 2 \\
6 & M & F & 54 & 53 & ID & MM (s) & 3 \\
7 & M & M & 48 & 45 & ID & CLL (s) & 1 \\
8 & M & M & 49 & 46 & ID & MM (s) & 3 \\
9 & M & M & 45 & 49 & ID & AML (s) & 1 \\
10 & M & M & 36 & 43 & ID & SAA (s) & 4 \\
11 & F & F & 55 & 45 & ID & MM (s) & 3 \\
12 & M & M & 59 & 52 & ID & CML (a) & 5 \\
13 & M & F & 24 & 20 & ID & NHL (s) & 1 \\
14 & M & F & 30 & 28 & ID & CML (a) & 1 \\
15 & M & M & 41 & 44 & ID & CLL (s) & 1 \\
16 & M & F & 45 & 42 & ID & CML (s) & 1 \\
17 & M & F & 32 & 47 & MUD & ALL (s) & 2 \\
18 & F & F & 53 & 66 & ID & MDS (s) & 1 \\
19 & M & F & 43 & 36 & ID & CML (s) & 1 \\
\hline
\end{tabular}

Conditioning: $1=$ total body irradiation $800 \mathrm{cGy}+$ cyclophosphamide; $2=$ total body irradiation $1000 \mathrm{cGy}+$ cyclophosphamide; $3=$ total body irradiation $800 \mathrm{cGy}+$ high-dose melphalan; $4=\mathrm{ATG}+$ cyclophosphamide; $5=$ busulphan + cyclophosphamide. All patients received cyclosporin A and methotrexate as GVHD prophylaxis. Diagnoses: ALL: acute lymphoblastic leukaemia; AML: acute myeloid leukaemia; CLL: chronic lymphocytic leukaemia; CML: chronic myeloid leukaemia; MDS: myelodysplastic syndrome; MM: multiple myeloma; NHL: nonHodgkin's lymphoma; SAA: severe aplastic anaemia. (s): standard risk (first chronic phase or first complete remission); (a): advanced risk (CML in accelerated or blastic phase, second or later remission). Donor type: MUD = matched unrelated donor; ID = identical sibling donor. 
and were not allowed to exceed the maximal concentration of $4 \times 10^{5}$ cells $/ \mathrm{ml}$ (Shih et al, 1983). This cell line was kept in a humidified atmosphere with $5 \% \mathrm{CO}_{2}$ at $37^{\circ} \mathrm{C}$. They were used to detect IL-2 in HTLp supernatants 2 or $3 \mathrm{~d}$ after the last culture to avoid an elevated background.

Limiting dilution assay for HTLp frequency determination. IL-2 secretion from donor lymphocytes was evaluated after in vitro stimulation with patient peripheral blood mononucleated cells (PBMNC). All cells used in the HTLp assay were thawed on the test day and washed three times. Responding cells from the donor were diluted to obtain a final concentration of $8 \times 10^{4}$ cells/well $/ 100 \mu$ l. These cells were plated in round-bottom plates and serially two-fold diluted with the last dilution at $2.5 \times 10^{3}$ cells/well. Stimulating cells from the patient were irradiated $(20 \mathrm{~Gy}$; rate $29.6 \mathrm{~Gy} / \mathrm{min}$, source of $\gamma$ radiation ${ }^{137} \mathrm{Cs}$ ) and $10^{5}$ cells in $100 \mu \mathrm{l}$ were added to responding cells. 24 replicates of each dilution were set up. The following controls were set up: 24 wells with stimulating cells alone for determination of positivity threshold and 16 replicates with responding cells alone. The stimulating capacity of patient cells was evaluated with 16 wells containing responding cells from two unrelated HLA-mismatched healthy volunteer controls. The responding capacity of donor cells was evaluated with the same controls irradiated to serve as stimulating cells. Autologous IL-2 secretion was evaluated by culturing 16 replicates of donor or recipient PBMNC with autologous irradiated cells.

The cultures were kept in DMEM supplemented with $10 \%$ heat-inactivated normal $A B$ human pooled serum, glutamine $(1.5 \mathrm{~mm})$, penicillin $(50 \mathrm{U} / \mathrm{ml})$, streptomycin $(50 \mu \mathrm{g} / \mathrm{ml})$ and gentamycin $(500 \mu \mathrm{g} / \mathrm{ml})$, in a humidified atmosphere with $5 \% \mathrm{CO}_{2}$ at $37^{\circ} \mathrm{C}$ for $72 \mathrm{~h}$. After $72 \mathrm{~h}, 100 \mu$ of the supernatant were transferred to new flat-bottom plates and frozen at $-70^{\circ} \mathrm{C}$ until further analysis.

On the day of analysis, plates containing supernatants were slowly thawed $\left(4^{\circ} \mathrm{C}\right.$ for $6 \mathrm{~h}, 37^{\circ} \mathrm{C}$ for $\left.30 \mathrm{~min}\right)$. IL-2 growth dependent cells (A9.12 murine cell line) were washed three times in $50 \mathrm{ml}$ culture medium and starved of IL-2 for 4-6h. They were diluted in an enriched medium (normal culture medium supplemented with $7 \mathrm{~mm}$ sodium pyruvate and $3 \mathrm{~mm} 2$-mercaptoethanol) to obtain a final concentration of $8 \times 10^{4}$ cells $/ \mathrm{ml}$. $50 \mu$ of this solution were then added to HTLp supernatants. To assess A9.12 cells responsiveness to $\mathrm{IL}-2$ they were incubated in a distinct culture plate with known amounts of rhIL-2, the concentration of which ranged from 0 to $100 \mathrm{lU} / \mathrm{ml}$.

Culture plates were incubated in an humidified atmosphere, $5 \% \mathrm{CO}_{2}$ at $37^{\circ} \mathrm{C}$ for $42 \mathrm{~h}$ with the last $18 \mathrm{~h}$ in the presence of ${ }^{3} \mathrm{H}$-thymidine $(74 \mathrm{kBq} /$ well). Thymidine incorporation was measured by harvesting cells to filters and counting $\beta$ radiation with a $\beta$ scintillation counter (Beckman LS 6000 SE or Topcount, Packard Instruments). When HLA-mismatched controls were negative for IL-2 secretion, the test was considered as invalid and not included in this study.

Antibodies. Monoclonal mouse antibodies of the following specificity were used: HLA-DR (clone B-F1, FITC labelled, from Serotec), CD 80 (clone L307.4, PE labelled, from Becton Dickinson), mouse IgG1 (FITC or PE labelled, from Becton Dickinson).

Immunofluorescence staining. On the day that the limiting

Table II. HTLp frequency estimation and patients' clinical evolution.

\begin{tabular}{rllllll}
\hline UPN & $\begin{array}{l}\text { HTLp } \\
\text { frequency }\end{array}$ & Cl $95 \%$ & P & aGVHD & CGVHD & Clinical outcome \\
\hline 3 & 14487 & $10952-19163$ & $>0 \cdot 3$ & IV & (na) & Death 22 (1) \\
12 & 15270 & $11701-19927$ & $>0 \cdot 7$ & II & (na) & Death 104 (2) \\
9 & 22100 & $16590-29440$ & $<0 \cdot 1$ & II & - & Death 277 (3) \\
18 & 38903 & $29595-51137$ & $<0 \cdot 1$ & II & - & Alive 753 \\
11 & 54505 & $33125-89686$ & $>0 \cdot 95$ & II & Limited & Alive 608 \\
15 & 55848 & $30987-100655$ & $>0 \cdot 3$ & II & Limited & Alive 841 \\
17 & 65113 & $47156-89906$ & $<0 \cdot 1$ & II & - & Death 173 (4) \\
10 & 74657 & $56965-97766$ & $>0 \cdot 5$ & 0 & Limited & Alive 445 \\
1 & 83830 & $44907-156490$ & $>0 \cdot 2$ & 0 & - & Alive 939 \\
7 & 99031 & $67982-144263$ & $>0 \cdot 5$ & 0 & - & Alive 885 \\
5 & 118698 & $80310-175436$ & $>0 \cdot 3$ & II & (na) & Death 83 (1, 5) \\
16 & 124877 & $85320-182773$ & $>0 \cdot 5$ & II & Limited & Alive 331 \\
8 & 161831 & $80985-323383$ & $>0 \cdot 5$ & 0 & - & Alive 1166 \\
14 & 206860 & $134933-317128$ & $>0 \cdot 5$ & 0 & Limited & Alive 1131 \\
4 & 276457 & $169256-451555$ & $>0 \cdot 2$ & I & - & Alive 243 \\
2 & 277311 & $191959-400614$ & $>0 \cdot 1$ & 0 & - & Alive 187 \\
19 & 311956 & $162818-597699$ & $>0 \cdot 1$ & II & Limited & Alive 235 \\
13 & 412343 & $196622-864740$ & $>0 \cdot 3$ & 0 & - & Alive 334 \\
6 & 414621 & $215431-797985$ & $>0 \cdot 9$ & III & (na) & Death 190 (1, 2,6)
\end{tabular}

Death causes: 1: GVHD; 2: pneumonitis; 3: cerebral aspergillosis; 4: relapse; 5: haemolytic uraemic syndrome; 6: denutrition. CGVHD (na): not applicable. 
Table III. Median HTLp frequency comparison between patient subgroups.

\begin{tabular}{lrlrr}
\hline Patient subgroup & $\begin{array}{l}\text { 1/HTLp } \\
\text { (median) }\end{array}$ & \multicolumn{1}{l}{$\begin{array}{l}\text { 1/HTLp } \\
\text { (range) }\end{array}$} & N & P \\
\hline aGVHD 0-I & 184346 & $74657-412343$ & 8 & 0.008 \\
aGVHD II-IV & 55848 & $14487-414621$ & 11 & \\
Alive & 143354 & $54505-412343$ & 13 & $<0.001$ \\
Deceased & 22100 & $14487-414621$ & 6 & \\
Donor CMV ${ }^{-}$patient CMV & \\
Donor and patient CMV & 79244 & $22100-118698$ & 6 & 0.09 \\
\hline
\end{tabular}

$P$ values are obtained using the Mann-Whitney test. Median follow-up for alive patients is 20 months (range 6-39).

dilution assay was set up, $10^{5}$ stimulating cells were incubated with $1 \mu \mathrm{g}$ antibody for $20 \mathrm{~min}$ at $4^{\circ} \mathrm{C}$ (final volume $110 \mu$ l). The cells were then washed twice with PBS and analysed immediately. Isotype-specific negative controls were performed in all experiments.

Flow cytometry. Flow cytometric assays were carried out using a Becton Dickinson FACSCAN ${ }^{\circledR}$. Data were acquired and analysed using the Cell Quest software. Surface marker expression was analysed in the mononucleated population. At least $10^{4}$ events were analysed for each patient.

Statistical analysis. Evaluation of HTLp frequency was obtained using the $\chi^{2}$ minimalization for the zero term of Poisson distribution between the number of responder cells and the fraction of negative wells (Taswell, 1984). The result was calculated using the GLIM software (NAG Ltd, Oxford, U.K.). $P$ values $>0 \cdot 1$ were considered as fitting the single hit kinetic from Poisson model.

In HTLp tests the threshold of positivity for IL-2 secretion was obtained from A 9.12 proliferation observed in the 24 replicates set up without responder cells as follows: percentile $75+$ (percentile 75 - percentile 25) (Barnett et al, 1984).

Comparison between median frequency obtained in different subgroups of patients was evaluated using the Mann-Whitney test. Disease-free survival probability was estimated according to Kaplan \& Meier (1958). The relationship between donor sex or disease and GVHD occurrence or survival was tested with Fisher's exact test or with the chi-square test.

\section{RESULTS}

HTLp frequency as a predictive test for GVHD occurrence Donor anti-host HTLp frequency estimation was obtained for 19 patients (Table II). The median frequency was $1 / 99031$ (range $1 / 14487$ to $1 / 414621$ ). HTLp frequency was compared with acute GVHD occurrence, donor and patient CMV previous infection and survival. A statistically significant difference was observed between patients with or without acute GVHD grade II-IV (median 1/55848 v 1/ 184346; $P=0.008$ ), and between long-term survivors and deceased patients (median 1/143354 versus 1/22100; $\mathrm{P}<0.001)$. We also observed a trend to significance when
CMV-posititve patients had a seronegative donor (median $1 /$ 79244 v 1/276457 for pairs with both patient and donor seropositive for $\mathrm{CMV} ; \mathrm{P}=0.09$ ). We also correlated disease stage (standard or advanced) and donor sex with GVHD incidence, overal outcome and HTLp test positivity and we did not find any significant correlation. These comparisons are summarized in Table III.

HTLp test was considered positive when more than one donor IL-2 secreting lymphocyte among 150000 PBMNC could be detected. The test showed $82 \%$ sensitivity, $63 \%$ specificity, $75 \%$ positive predictive value and $71 \%$ negative predictive value. When donor HTLp frequency was compared with survival, we found $83 \%$ sensitivity and $85 \%$ negative predictive value. Therefore this test could also predict post-transplantation survival. In this series of patients probability of disease-free survival was 0.57 .

HLA-DR and CD 80 expression by stimulating cells In 16 patients' PBMNC, HLA-DR and CD 80 expression was

Table IV. Percentage of positive PBMNC stimulating cells for CD80 or HLA-DR molecule expression.

\begin{tabular}{rlll}
\hline & $\begin{array}{l}\text { HLA-DR positive } \\
\text { UPN }\end{array}$ & $\begin{array}{l}\text { CD80 positive } \\
\text { PBMNC (\%) }\end{array}$ & $\begin{array}{l}\text { 1/HTLp } \\
\text { frequency }\end{array}$ \\
\hline 3 & $16 \cdot 5$ & $2 \cdot 5$ & 14487 \\
12 & $13 \cdot 6$ & $0 \cdot 46$ & 15270 \\
18 & $7 \cdot 34$ & $1 \cdot 21$ & 38903 \\
11 & $23 \cdot 5$ & 7 & 54505 \\
15 & $67 \cdot 7$ & $1 \cdot 5$ & 55848 \\
17 & 10 & $0 \cdot 16$ & 65113 \\
10 & $5 \cdot 34$ & $2 \cdot 7$ & 74657 \\
7 & $38 \cdot 2$ & $4 \cdot 3$ & 99031 \\
5 & 46 & 3 & 118698 \\
16 & $27 \cdot 5$ & 9 & 124877 \\
8 & $50 \cdot 5$ & $0 \cdot 8$ & 161831 \\
14 & 31 & $0 \cdot 4$ & 206860 \\
2 & $14 \cdot 1$ & $0 \cdot 8$ & 277311 \\
19 & $11 \cdot 4$ & $0 \cdot 7$ & 311956 \\
13 & $37 \cdot 5$ & $0 \cdot 6$ & 412343 \\
6 & 22 & $1 \cdot 1$ & 414621 \\
\hline
\end{tabular}


292 M. Winandy et al
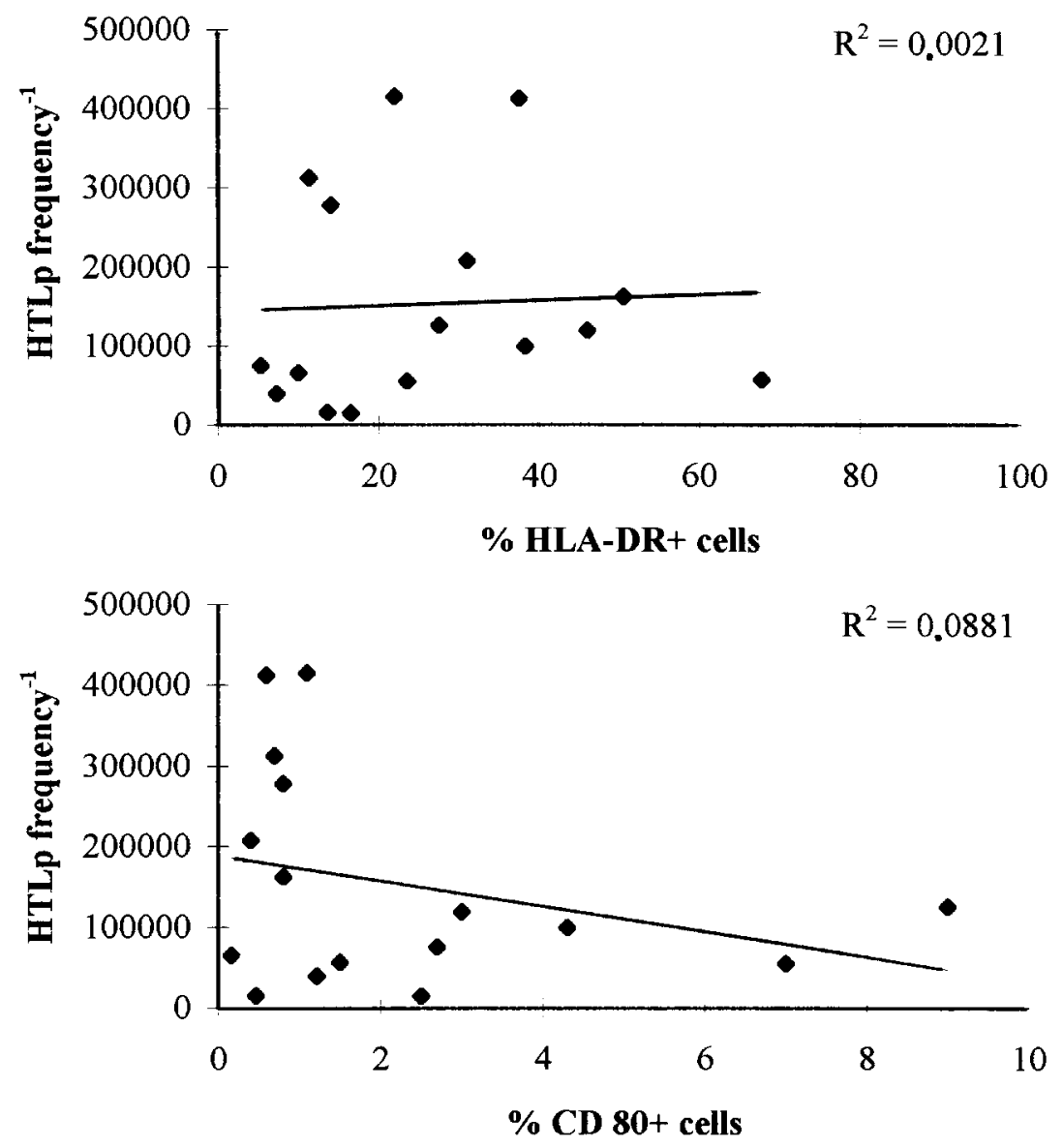

Fig 1. Correlation between HTLp frequency and HLA-DR or CD80 expression by patient's PBMNC.

measured by flow cytometry to assess the antigen presentation and co-signalling capacity of stimulating cells. We observed a wide range of percentages of positive cells for these two molecules (HLA-DR: median 22.7, range 67.7-5.3; CD 80: median $1 \cdot 1$, range $9-0 \cdot 16$ ) (Table IV). No correlation was found between HTLp frequency and HLA-DR or CD80 expression (Fig 1); correlation coefficients were 0.0021 and 0.0881 respectively.

\section{DISCUSSION}

Donor pretransplant HTLp frequency was performed using an established protocol with minor modifications (Schwarer et al, 1993) in 19 patients who received allogeneic BMT.

The first modification was the choice of IL-2-dependent cell line for the revelation of secreted IL-2 in HTLp tests. The A 9.12 murine cell line was compared with the more usual CTLL-2 cell line. It was found to be more sensitive and reliable for recombinant IL-2 detection and for HTLP supernatant screening (Winandy et al, 1998). Other investigators also have chosen this cell line for the same reasons (Lewalle et al, 1996; Keever-Taylor et al, 1997). However, this cell line sometimes gave a positive signal in negative control wells (containing only stimulating cells) in HTLp tests. These positive values may be explained by IL-2 secretion by stimulating cells, as reported by other investigators (Hornick et al, 1996; Reiseater et al, 1996). Therefore the positivity threshold for determining IL-2positive wells had to take these outlying values into account. The threshold was obtained as follows: percentile $75+$ (percentile 75 - percentile 25) from the 24 negative control culture wells. This method enabled the positivity threshold to be based on the median value from negative control wells, and was less influenced by the outlying values than the more classical method (mean +3 standard deviations) (Barnett et al, 1984).

Some authors considered the HTLp test positive when they detected more than one IL-2 secreting T cell in 100000 PBMNC (Theobald et al, 1992; Schwarer et al, 1993, 1994). We lowered this threshold because the majority of our patients had a related donor, with genetical HLA identity, and probably closer identity for minor antigens than might be the case in unrelated donor-recipient pairs. In these conditions donor lymphocytes showed a lower IL-2 secre tion. This was confirmed by our observation of seven unrelated and three related HLA-identical healthy controls. Median HTLp frequency was $1 / 104700$ and 1/189500, respectively. This observation outlined the importance of non-HLA antigenic disparities. The majority of GVHD patients from this series had a pretransplant HTLp frequency $>1 / 150000$ PBMNC, probably reflecting a higher minor antigen disparity degree between donor and recipient. 
The test results were closely related with GVHD and survival, as shown previously (Theobald et al, 1992; Schwarer et al, 1993, 1994). However, we observed a lack in outcome prediction for patient 6 whose HTLp test was negative, but who died as a consequence of aGVHD gradellI and infectious complications. This fatal outcome may be explained by the fact that multiple myeloma patients generally have a greater risk for post-transplant complications.

There was also a trend to an increased HTLp frequency for CMV seropositive patients with a seronegative donor. It is known that this virus induces the expression of viral antigens on host cells that may constitute minor antigens (Boström et al, 1992; Appleton \& Sviland, 1993; Appleton et al, 1995). This trend for increasing HTLp frequency in CMV-positive recipients confirms the importance of such antigens as stimulating allogeneic responses. We did not find any correlation between disease stage or donor sex with the incidence of acute GVHD, nor with a favourable outcome after transplantation.

Enumeration of cytotoxic $\mathrm{T}$ lymphocytes precursors (CTLp) has been shown to be related to acute GVHD occurrence and survival by several groups (Kaminski et al, 1989; Potolicchio et al, 1996; Speiser et al, 1996; KeeverTaylor et al, 1997). High CTLp frequencies were tightly related to HLA class I mismatches and high HTLp frequencies with class II mismatches (DRB1 or DPB1 alleles). It has to be outlined that the association was made with GVHD grade III-IV and not with grade II-IV. Grade II is generally improved with corticosteroids but may cause important morbidity. It seems important to try to predict also gradeII GVHD. Taken together, the data about CTLp and HTLp frequencies are useful as functional in vitro tests, related to HLA and non-HLA antigenic disparities. Helper T lymphocytes act in the afferent branch of GVHD and cytotoxic T lymphocytes in the efferent branch (Theobald, 1995).

Investigations were made to assess stimulating capacity of patient's PBM NC by analysing HLA-DR and CD80 expression by flow cytometry. These two molecules are essential for antigen presentation and T-cell stimulation. CD80 and CD87 have been shown to be essential for the development of in vitro allogeneic T-cell responses (Knulst et al, 1994; Van Gool et al, 1994; Gribben et al, 1996). These two molecules being highly inducible on lymphocytes by antigenic or lymphokine stimulation, the question was whether their expression level could influence IL-2 secretion revealed by the HTLp test. None of these parameters was related to pretransplant HTLp frequency. Our results show a wide range of individual HLADR expression. This may be explained by the lymphocyte to monocyte ratio, which was low in some samples. CD80 expression was low, as expected for resting lymphocytes. These observations allowed us to consider our samples as homogenous regarding allogeneic stimulating capacity, and the elevated values for HTLp were therefore due to true antigenic stimulation. CD80 and HLA-DR expression as assayed here will evaluate the sample as a whole and will miss infrequent cells which express these molecules strongly. The lack of correlation of expression in the whole sample with HTLp frequency does therefore not mean that there would be no correlation with CD80 and HLA-DR expression by a rare population of stimulating cells.

In conclusion, we confirm that the HTLp test is a suitable tool to detect antigenic differences between HLA-matched donor and patient. It may help in donor selection and prophylactic strategy because it is useful in detecting high risk patients for acute GVHD and post-transplant mortality.

\section{ACKNOW LEDGMENTS}

We thank Dr P. Martiat for attentively reading the manuscript. This work was supported by F.N.R.S. (grant Télévie $\mathrm{nr} 7.4509 .93$ and 7.4538.95), Salus Sanguinis Foundation and the Belgian Red Cross.

\section{REFEREN CES}

Appleton, A.L. \& Sviland, S. (1993) Pathogenesis of GVHD: role of herpes viruses. Bone M arrow Transplantation, 11, 349-355.

Appleton, A.L., Sviland, S., Peiris, J.S.M., Taylor, C.E., Wilkes, J., Green, M.A., Pearson, A.D.J., Proctor, S.J., Hamilton, P.J., Cant, A.J. \& Malcolm, A.J. (1995) Role of target organ infection with cytomegalovirus in the pathogenesis of GVHD. Bone Marrow Transplantation, 15, 557-561.

Aschan, J., Ringdén, O., Andström, E., Ljungman, P., Lönnqvist, B. \& Remberger, M. (1994) Individualised prophylaxis against GVHD in leukemic marrow transplant recipients. Bone Marrow Transplantation, 14, 79-87.

Barnett, V. \& Lewit, T. (1984) Outliers in Statistical Data, 2nd edn. Wiley, New York.

Boström, L., Ringdén, O. \& Forsgren, M. (1992) Strong donor mononuclear cell reactivity for herpes simplex virus antigen in immune donor/recipient pair is associated with GVHD. Transplantation Proceedings, 24, 376-677.

Bunjes, D., Theobald, M., Nierle, T., A rnold, R. \& Heimpel, H. (1995) Presence of host-specific IL-2-secreting $T$ helper cell precursors correlates closely with active primary and secondary chronic GVHD. B one M arrow Transplantation, 15, 727-732.

Ferrara, J.L.M. \& Deeg, H.J. (1991) Mechanisms of disease: GVHD. $\mathrm{N}$ ew England Journal of M edicine, 324, 667-674.

Gribben, J.G., Guinan, E.C., Boussiotis, V.A., Ke, X.Y., Linsley, L., Sieff, C., Gray, G.S., Freeman, G.J. \& Nadler, L.M. (1996) Complete blockade of B7 family mediated costimulation is necessary to induce human alloantigen-specific anergy: a method to ameliorate graft-versus-host disease and extend the donor pool. Blood, 87, 4887-4893.

Hansen, J.A., Petersdorf, E.W., Choo, S.Y., Martin, P.J. \& Anasetti, C. (1995) Marrow transplantation from HLA partially matched relatives and unrelated donors. Bone M arrow Transplantation, 15, (Suppl. 2), s128-s129.

Hornick, P., Brookes, P., Mason, P., Taylor, K.M., Yocoub, M.Y., Batchelor, J.R., Rose, M.L. \& Lechler, R.I. (1996) Limiting dilution analysis: increasing the sensitivity and specificity of alloreactive $T$ helper cell assay by abrogating 'unwanted' IL-2 production. Human Immunology, 47, 130.

Kaminski, E., Hows, J., Man, S., Brookes, P., Hughes, T., Avakian, O., Goldman, J.M. \& Batchelor, J.R. (1989) Prediction of GVHD by frequency analysis of cytotoxic $T$ cells after unrelated donor bone marrow transplantation. Transplantation, 48, 608-613.

Kalhs, P. (1993) GVHD: risk factors. Bone M arrow Transplantation, 12, (Suppl. 4), s48-s50.

Kaplan, E.L. \& Meier, P. (1958) Nonparametric estimations from 


\section{M. Winandy et al}

incomplete observations. Journal of the American Statistical Association, 53, 457-481.

Keever-Taylor, C.A., Passweg, J., Kawanishi, Y., Casper, J., Flomenberg, N. \& Baxter-Löwe, L.A. (1997) Association of donor-derived host-reactive cytolytic and helper T cells with outcome following alternative donor T-cell-depleted bone marrow transplantation. Bone M arrow Transplantation, 19, 1001-1009.

Kelemen, E., Szebeni, J. \& Petranyi, G. (1993) GVHD in bone marrow transplantation: experimental, laboratory and clinical contributions of the last few years. International Archives of Allergy and Immunology, 102, 309-320.

Knulst, A.C., Tibbe, G.J.M., Noort, W.A., Bril-Bazuin, C., Benner, R. \& Savelkoul, H.F.J. (1994) Prevention of lethal graft-versus-host disease in mice by monoclonal antibodies directed against $T$ cells or their subsets. I. Evidence for the induction of a state of tolerance based on suppression. B one M arrow Transplantation, 13, 293-301.

Lewalle, P., Hensel, N., Guimares, A., Couriel, D., Jiang, Y.Z., Mavroudis, D. \& Barrett, A.J. (1996) Helper and cytotoxic lymphocyte responses to chronic myeloid leukaemia: implications for adoptive immunotherapy with $\mathrm{T}$ cells. British Journal of Haematology, 92, 587-594.

Mickelson, E.M., Longton, G., Anasetti, C., Petersdorf, E., Martin, P., Guthrie, L.A. \& Hansen, J.A. (1996) Evaluation of the mixed lymphocyte culture (MLC) assay as a method for selecting unrelated donors for marrow transplantation. Tissue Antigens, 47, 27-36.

Potolicchio, I., Brookes, P.A., Madrigal, A., Lechler, R.I. \& Sorrentino, R. (1996) HLA-DPB1 mismatch at position 69 is associated with high helper $\mathrm{T}$ lymphocyte precursor frequencies in unrelated bone marrow transplant pairs. Transplantation, 62 1347-1352.

Przepiorka, D., Weisdorf, D., Martin, P., Klingemann, H.G., Beatty, P., Hows, J. \& Thomas, E.D. (1995) Consensus conference on GVHD grading. Bone M arrow Transplantation, 15, 825-828.

Reiseater, A.V., Thorsby, E. \& Brinchmann, J.E. (1996) Analysis of alloreactive $T$ lymphocyte precursor frequencies: influence of interleukin-2 produced by the stimulating cells. Journal of Immunological M ethods, 189, 65-70.

Schwarer, A., Jiang, Y.Z., Deacock, S., Brookes, P.A., Barrett, A.J., Goldman, J.M., Batchelor, J.R. \& Lechler, R.I. (1994) Comparison of helper and cytotoxic antirecipient $T$ cell frequencies in unrelated bone marrow transplantation. Transplantation, 58, 1198- 1203 .

Schwarer, A.P., Jiang, Y.Z., Brookes, P.A., Barrett, A.J., Batchelor, J.R., Goldman, J.M. \& Lechler, R.I. (1993) Frequency of anti-recipient alloreactive helper T-cell precusor in donor blood and GVHD after identical-sibling bone marrow transplantation. Lancet, $\mathbf{3 4 1}$, 203-205.
Segall, M., Noreen, H., Edwins, L., Haake, R., Shu, X. \& Kersey, J. (1996) Lack of correlation of MLC reactivity with acute graftversus-host disease and mortality in unrelated bone marrow transplantation. Human Immunology, 49, 49-55.

Shih, C.C.Y., Truitt, R.L., Abramoff, P. \& Bortin, M.M. (1983) Relationship between IL-2 receptors and cyclosporine-induced suppression of $\mathrm{T}$ leukemia and $\mathrm{T}$ helper cells. Transplantation Proceedings, 15, (Suppl. 1), 2394-2397.

Speiser, D.E., Löliger, C.C., Siren, M.K. \& Jeannet, M. (1996) Pretransplant cytotoxic donor T-cell activity specific to patient HLA class I antigens correlating with mortality after unrelated bone marrow transplantation. British Journal of Haematology, 93, 935-939.

Spencer, A., Brookes, P.A., Kaminski, E., Hows, J.M., Szydlo, R.M., van Rhee, F., Goldman, J.M. \& Batchelor, J.R. (1995a) CTLp frequency analyses in bone marrow transplantation with volunteer unrelated donors: value in donor selection. Transplantation, 59, $1302-1308$.

Spencer, A., Szydlo, R.M., Brookes, P.A., Kaminski, E., Rule, S., van Rhee, F., Ward, K.N., Hale, G., Waldmann, H., Hows, J.M., Batchelor, J.R. \& Goldman, J.M. (1995b) Bone marrow transplantation for chronic myeloid leukemia with volunteer donors using ex vivo or in vivo T-cell depletion: major prognostic impact of HLA class I identity between donor and recipient. Blood, 86, 3590- 3597.

Taswell, C. (1984) Limiting dilution assays for the determination of immunocompetent cell frequencies. III. Validity tests for single-hit Poisson model. Journal of Immunological M ethods, 72, 29-40.

Theobald, M., Nierle, T., Bunjes, D., Arnold, R. \& Heimpel, H. (1992) Host-specific IL-2-secreting T cell precursors as predictors of acute GVHD in bone marrow transplantation between HLA-identical siblings. New England Journal of M edicine, 327, 1613-1617.

Theobald, M. (1995) Allorecognition and GVHD. Bone Marrow Transplantation, 15, 489-498.

van Bekkum, D.W. (1991) What is GVHD? B one M arrow Transplantation, 7, (Suppl. 2), s110-s111.

van der Meer, A., Joosten, I., Ruiter, J. \& Allebes, W.A. (1997) A single $\left[{ }^{3} \mathrm{H}\right]$ thymidine-based limiting dilution analysis to determine HTLp and CTLp frequencies for bone marrow donor selection. Bone M arrow Transplantation, 20, 149.

Van Gool, S.W., de Boer, M. \& Ceuppens, J.L. (1994) The combination of anti-B7 monoclonal antibody and cyclosporin $A$ induces alloantigen-specific anergy during a primary mixed lymphocyte reaction. Journal of Experimental M edicine, 179, 715-720.

Winandy, M., Lewalle, P., Deneys, V., Ferrant, A. \& De Bruyère, M. (1998) Improved interleukin-2 detection for determination of helper $\mathrm{T}$ lymphocyte precursor frequency in limiting dilution assay. Journal of Immunological M ethods, 215, 81-94. 